\title{
A survey of GFRP composite leaf spring
}

\author{
S. Rajesh ${ }^{1 *}$, S. Nakkeran ${ }^{2}$, G. B. Bhaskar ${ }^{1}$ \\ ${ }^{1}$ Department of Mechanical Engineering, Tagore Engineering College, Chennai - 127 \\ ${ }^{2}$ Department of Mechanical Engineering, Bharath University, Chennai - 73 \\ *Corresponding author E-mail: rajeshbmm@yahoo.com
}

Copyright $\odot 2014$ S.Rajesh et al. This is an open access article distributed under the Creative Commons Attribution License, which permits unrestricted use, distribution, and reproduction in any medium, provided the original work is properly cited.

\begin{abstract}
Although leaf springs are one of the oldest suspension components, they are still frequently used in the automobile vehicles. Weight reduction is the main focus in the automobile industries. Weight reduction can be achieved primarily by the introduction of better materials, design optimization, and better manufacturing processes. The achievement of weight reduction with adequate improvement of mechanical properties has made composite a very good replacement material for conventional steel. Selection of material is based on the cost and strength of material. The composite materials have more elastic strain energy, storage capacity and high strength to weight ratio compared to steel. This paper briefs about the research carried out for the part of three decades on design, analysis, and selection of material, experiments and fabrication of composite leaf spring.
\end{abstract}

Keywords: Composite Leaf Spring, Composite Materials, Finite Element Analysis, Weight Reduction, Glass Fiber Reinforced Plastic (GFRP).

\section{Introduction}

The automobile industries have shown increased interest in the replacement of steel springs with composite leaf spring because of the general characteristics possessed by the composite material, which are found to be superior. In order to conserve natural resources and economize energy, weight reduction has been the main focus of automobile manufacturer in the present scenario. The suspension of leaf spring is one of the potential items for weight reduction in automobile as it accounts for ten to twenty percent of the unsprung weight. This helps in achieving the vehicle with improved riding qualities. The introduction of composite materials has made it possible to reduce the weight of the leaf spring without any reduction on load carrying capacity and stiffness. So the composite materials are now used in automobile industries. Composite materials have more elastic strain energy, storage capacity and high strength to weight ratio as compared to those of steel. Use of composite material as leaf spring, not only results in the reduction of weight but also ensures safety and cost reduction.

\section{Modelling and analysis of composite leaf spring}

[49] fabricated of natural fiber reinforced composite/ Jute (NFRC/JFRC) mono composite leaf spring and glass fiber reinforced composite (GFRC) mono leaf spring using hand layup method. The testing was performed experimentally with the help of Universal Testing Machine (UTM) and by finite element analysis (FEA) using ANSYS. From the results it was found out that by compared the GFRC leaf spring, the NFRC composite leaf spring has less stress compared to steel and the spring weight also reduced to 60 to $70 \%$. The NFRC leaf spring resulted reduction in deflection and stresses without compromising stiffness as experimentally and analytically.

[34] designed of EN45 parabolic leaf spring used by light commercial vehicle. A three layer parabolic leaf spring of EN45 has been taken for his work.The CAD modeling of parabolic leaf spring has been done in CATIA V5 and analysis was done by ANSYS -11. The finite element analysis (FEA) of the leaf spring was carried out initially discretizing the model into finite number of elements and the nodes by applying the boundary conditions. A correlation of CAE analysis with experimental results taken at industrial laboratory has been provided with the work. By 
comparing the FEA with experimental it gives very close results providing the validation of FEA model as well as the work.

[41] investigated the static and fatigue behaviors of steel and composite multi leaf spring using the ANSYS V12 software. The same dimensions of existing conventional leaf spring of a light commercial vehicle were used to design composite multi leaf spring for two materials, E- glass fiber / epoxy and E- glass fiber/ Vinyl ester. The design constraints were bending stresses, deflection and fatigue life. From the results it showed that by comparing the steel leaf spring, the designed composite spring has much lower bending stresses and deflections, higher in fatigue life cycles.

[9] investigated, $20 \mathrm{wt} \%$ short glass fiber reinforced polypropylene (SFPP), $20 \mathrm{wt} \%$ long glass fiber reinforced polypropylene (LFPP) and unreinforced polypropylene (UFPP) Leaf spring which were obtained from Saint Gobain and fabricated by injection molding process. Creep performance of the molded leaf spring was evaluated with the aid of inhouse developed fixture and suitably integrated with the servo hydraulic testing machine (Instron 8801). Test results revealed that HRZ model was sufficient enough to predict short-time flexural creep performance of engineering products over wide range of stress. Test results also confirmed the suitability of long fiber reinforced thermoplastic material for creep application over other considered materials.

[36] Introduced the composite material, in place of steel in the conventional leaf spring. Research has indicated that the results of E-Glass/Epoxy were found with good characteristics for storing strain energy. The model of leaf spring was created in Pro-E and the analysis was carried out by using ANSYS 10.0 software. These results can be used for comparison with the conventional steel leaf spring. In the result they concluded that deflection of composite leaf spring was less as compared to steel leaf spring with sam load condition. Conventional leaf spring was found to weigh $23 \mathrm{~kg}$, whereas E-glass/Epoxy mono leaf spring weighs only $3.59 \mathrm{~kg}$, indicating reduction in weight by $84.40 \%$.

[7] used a four - leaf spring in the rear suspension system of light vehicles and analyzed using ANSYS V5.4 software. The finite element results showing stresses and deflections verified the existing analytical and experimental solutions. Using the results of the steel leaf springs, a composite one made from fiberglass with epoxy resin was designed and optimized. The design constraints were stresses (Tsai - Wu failure criterion) and displacements. The results showed that an optimum spring width decreases hyperbolically and the thickness increases linearly from the spring eyes towards the axle seat. Compared to the steel spring, the optimized composite spring has stresses that are much lower, the natural frequency was higher and the spring weight without eye units is nearly $80 \%$ lower.

[20] Designed, fabricated (molted and hoop wound) and tested a single leaf, variable thickness spring of glass fiber reinforced plastic (GFRP) with similar mechanical and geometrical properties to the multi leaf steel spring. A finite element program was used to model this behavior and the approximate leaf spring radius was found to be equal to 94 $\mathrm{cm}$, having a thickness varying from $4.5 \mathrm{~cm}$ at the centre to $2.45 \mathrm{~cm}$ at the ends, using composite materials made from woven fabric fiberglass/epoxy. The springs were subjected to a series of laboratory static loading tests. The test simulated a three - point bending test which was monitored continuously throughout the experiment. In addition two types of GFRP springs were fabricated. In first group, the eyeholes were integral parts of the mold, whereas in the second group, the eyeholes were molded separately after the curing of the laminate leaf spring. Moreover, GFRP springs were more flexible than steel springs. Also, during the test ride, noise and harshness were significantly reduced. In general, this study demonstrated that composite can be used for leaf springs for light trucks (jeeps) and meet the requirements, together with substantial weight saving.

[14] designed and manufactured a functional composite leaf spring by using uni-directional E- glass roving impregnated by an epoxy resin for solar powered light vehicle. This results in weight reduction and reduces the impact load transferred to the chasis evenly when the suspension reaches full deflection.

[1] in a composed two antagonistic non-linear springs. The elastic device which consists of two pairs of leaf spring working in bending conditions under large displacements. Owing to this geometric non-linearity, the global stiffness of the actuator can be adjusted by modifying the shape of the leaf spring. In this section a mathematical model of the aforementioned elastic device was developed. Fabrication of the prototype is important to notice that before testing the prototype, the deformed shape of one leaf spring was measured by means of a tridimensional coordinate measuring machine showing a similar profile as the one obtained from the mathematical model. The experimental set-up was conducted at the mechanical laboratory located at the department of applied mechanics in the University of Castilla-La Mancha in Spain. This paper also proposes a mathematical model that allows the leaf springs to be dimensioned for every specific purpose. A prototype of the spring has been built and tested. The experiments corroborate the model proposed for a wide range of use of the spring. On the other hand, the experimental results show different values than the mathematical model when the spring works close to its maximum load and stiffness. This was due to the fact that the protection system modifies the boundary conditions of the problem.

[24] designed and optimized composite laminate requires finding the minimum number of layers, and the best fiber orientation and thickness for each layer. To date, several optimization methods have been introduced to solve this challenging problem, which is often non-linear, non-convex, multimodal, and multidimensional, and might be expressed by both discrete and continuous variables. These optimization techniques can be studied in two parts: constant stiffness design and variable stiffness designs. This paper concentrated on the first part, which deals with composite laminates with uniform stacking sequence through their entire structure. The optimization techniques are classified into four categories: gradient-based methods, direct search and heuristic methods, specialized techniques, and hybrid methods. Finally, hybrid methods benefit from the advantages of all their constituent methods. The review of the main hybrid methods in this paper has highlighted their promising future. 
[43] modelling the leaf spring in the conventional way modelica standard library. It was able to capture the leaf spring characteristic and vehicle handling dynamics studies, which is resulted in less simulation time and easier to parametric the geometric position and to implement the suspension design, this enables user to add additional force elements as a damper to the leaf spring help to standardize the leaf spring model.

[25] used mathematical programming techniques. Which is the most widely used an artificial genetics approach for the design optimization of composite leaf spring. On applying the GA, the optimum dimensions of a composite leaf spring have been obtained, which contributes towards achieving the minimum weight with adequate strength and stiffness. A reduction of $75.6 \%$ weight is achieved when a seven-leaf steel spring was replaced with a mono-leaf composite spring under identical conditions of design parameters and optimization. A tailor made computer program using $\mathrm{C}$ has been developed to perform the optimization process, and to obtain the best possible design.

[26] investigated that bending can be significantly higher than the ultimate strain measured by tensile tests. A model for prediction of ultimate tensile strain to failure for composites with a random-fibre pattern subjected to 1-D and 2-D nonuniform stress states has been developed based on Weibull theory. To verify the model, the required Weibull parameters were determined by tensile tests for a specific material. These material data were used to predict ultimate strain in threeand four-point bending and in biaxial bending. When a two-parameter Weibull distribution was used, the agreement between predicted and measured median strain to failures was quite good. The distribution of strain to failures was also good and the predictions were always conservative.

[35] identified that the properties of engineering materials can be mapped, by displaying the ranges of mechanical, thermal, electrical and optical behavior they offer. These maps reveal that there are holes: some areas of property-space are occupied and others are empty. The holes can sometimes be filled and the occupied areas extended by making hybrids of two or more materials or of material and space. Particulate and fibrous composites are examples of one type of hybrid, but there are many others: sandwich structures, foams, lattice structures and more.

[12] conceived and produced a self-supporting city bus structure, conceived and produced in glass fiber reinforced plastic with modular composition criteria, was analysed in the static and dynamic field. The analysis was performed using finite element models using two different models that can be improved for further studies in connection with the development of the design to a final form. The structural behavior trends have been found both by analysing the static load bearing conditions considered as extreme, as well as obtaining the most significant vibration shapes. In this way improvements of the examined prototype have been obtained. The main results of this study are to show the actual feasibility of a self-supporting composite city bus.

[23] developed and investigated a nonlinear elastic model of leaf springs for the use in the computer simulation of multibody vehicle systems. The non-linear stiffness matrix is first developed for the finite element of each leaf and is used to determine the overall leaf spring stiffness matrix. The pre-stresses, the contact and friction that characterize the nonlinear behavior of leaf springs were discussed. The first contribution is the development of a new nonlinear elastic formulation, the second contribution is the development of a procedure to determine the initial pre-stressed configuration of the leaf spring, and the third contribution is the computer implementation of the proposed methods and the development of a detailed vehicle model based on the nonlinear leaf spring formulation.

[37] conducted finite element analysis with full bump load on 3-D model of composite multi leaf spring, using ANSYS 7.1. E-glass/epoxy was selected as spring material and was fabricated using Filament-winding machine. CLS was tested with an electro-hydraulic leaf spring test rig. A weight reduction of $68.15 \%$ was also achieved by using composite leaf spring. Fatigue life of composite leaf spring (10, 00,000 cycles) was found to be more than that of conventional steel leaf spring $(2,00,000$ cycles).

[15] presented a numerical model for the non-linear analysis of thick laminates. Using a multiplicative decomposition of the displacement vector in shell shape, the $3 \mathrm{D}$ problem was reduced to $2 \mathrm{D}$ problem. Although the total number of degrees of freedom is comparable to 3D was brick elements, this approach provides several advantages, eg a simplified mesh generation due to 2D- type data structure and better bending behavior. The computed results are good agreement with solutions in the literature. The problem of ill - conditioning which occurs for thin structures has to be solved. Furthermore, material nonlinear behavior due to matrix and fiber cracking has to be incorporated.

[40] studied micro failure as well as for the quality assurance of the composite material. As extremely high utility for the study of micro failure as well as for the quality assurance of the composite material. Using acoustic Emission (AE) technique. In order to make the AE techniques more useful, the following four studies have been performed. In situ failure techniques by SEM, dynamic strain loss measurement, Laser Raman spectroscopy and Thermo acoustic emission measurement. Based on the proper understanding of the micro failure mechanism of the composites through the above experiments, the AE technique has been successful in the development of automotive composite components. [16] presented about fatigue life prediction based on finite element analysis and variable amplitude loading (VAL) life. They simulated the variable amplitude loading for the fatigue life analysis. From the results, the fatigue damage using VAL has been predicted and the result was correlated with FEM.

[17] developed the detailed three dimensional finite element models of woven roving E-glass fabric composite elliptic spring, was developed using LUSAS finite element package (version 13.57). The material used for this project was woven fiberglass fabrics. This was because it has the widest range and the best control over thickness, weight and strength of all forms of fiberglass textiles. This offers the materials engineer a wide choice of controlling fabric properties to satisfy design needs and objectives. The fabricated semi elliptic spring was used to provide optimum 
hardness and shrinkage. The final fabricated composite elliptic spring model weighs app. $1.2 \mathrm{~kg}$ which improved the weight saving. The results showed that composite elliptical springs have better fatigue behavior than the conventional leaf and coil spring. Elliptical configuration successfully eliminates any hypothesis of delamination. The fabricated composite elliptic spring was constructed based on the optimization developed from the finite element analysis which has the ellipticity ratio of $(\mathrm{a} / \mathrm{b}=2)$ and resulting in a substantial weight saving.

[2] developed the details of a three-dimensional finite element model of a woven roving E-glass fabric composite elliptic spring, using the LUSAS finite element package (version 13.57). The study demonstrated that composite elliptical springs can be used for light and heavy trucks with substantial weight reduction. The results showed that the ellipticity ratio significantly influenced the design parameters. Composite elliptic springs with ellipticity ratios of $a / b=2$ had the optimum spring parameters.

[6] reproduced the identical load/deflection characteristics and the maximum load capacity of the steel disc spring while achieving significant mass savings. Design equations for steel disc springs were modified for a quasi-isotropic composite lay-up. The results show that accurate reproducibility of the steel springs, load-deflection characteristics could be achieved by using composites, with a corresponding mass savings of almost $80 \%$. The failure mode (on overloading the composite spring) consisted of radial fracture arising from the hoop stress as predicted by theory. The results of this study indicated that composites can satisfactorily replace steel in disc springs with significant mass savings.

\section{Experimental and investigation of composite leaf spring}

[19] designed a single leaf with variable thickness and width for the constant cross sectional area of unidirectional glass fiber reinforced plastic (GFRP) with similar mechanical and geometrical properties to the multi leaf spring, fabricated by hand layup technique and tested. Computer algorithm using C-language has been used for the design of constant cross section leaf spring. The finite element results using ANSYS software showing stresses and deflection were verified with analytical and experimental results. For the fabrication of mono composite leaf spring of E-glass epoxy, hand layup techniques were used. The experimental tests were carried on both steel and composite leaf spring and compared the results. It was found that composite leaf spring is more superior to steel leaf spring with a large weight reduction.

[39] described static and fatigue analysis of steel leaf spring and composite multi leaf spring made up of glass fiber reinforced polymer using life data analysis. The design constraints are stresses and defections. Finite element analysis with full dump load on 3D model of composite multi leaf spring was done using ANSYS 7.1 and analytical results were compared with experimental results. For the fabrication of leaves filament winding machine was used and assembled. The testing of steel leaf spring and composite leaf spring were carried out with the help of electro hydraulic leaf spring test rig. Design and experimental fatigue analysis of composite leaf spring were carried out using data analysis. It was found that compared to steel leaf spring, the composite leaf spring was found to have lesser stress, higher natural frequency than that of existing steel leaf spring. A weight reduction was also achieved using composite leaf spring. It was also concluded that fatigue life of composite is more than that of conventional steel leaf spring.

[8] reported the influences of reinforced fiber length on the performance of the injection moulded thermoplastic leaf spring Joint leaf springs were injection moulded from 20\% short glass fiber reinforced polypropylene (SFPP), 20\% long glass fiber reinforced poly propylene (LFPP) and unreinforced polypropylene (UFPP). Universal servo hydraulic testing facility was used for testing joint strength under static and dynamic conditions. Static and dynamic joint strength performance of discontinuous glass fiber reinforced polypropylene leaf spring with steel plate was experimentally investigated and the endurance strength of the leaf spring joints for all the materials was found to be significantly higher than the leaf spring. Long fiber leaf spring joint exhibit superior performance during high cycle fatigue conditions than short and unreinforced leaf spring joint. High notch sensitivity characteristics of long fiber reinforced polypropylene material contributed to this interior performance. Load deflection hysteresis plot of long fiber reinforced leaf spring joint under fatigue load condition exhibited a lesser amount of hole compared to that of short glass fiber and unreinforced leaf spring.

[28] presented the design evolution of a composite leaf spring for freight rail applications. Three designs of eye - end attachment for composite leaf springs are described. The material used was glass fiber reinforced polyester. Static testing and finite element analysis have been carried out to obtain the characteristics of the spring, Load - deflection curves and strain measurements as a function of load have been plotted for comparison with FEA predicted values. The main concern associated with the fist design was the delamination failure at the interface of the fibers that have passed around the eye and the spring body, even though the design can withstand $150 \mathrm{kN}$ static proof load and one million cycles fatigue load. The second design feature was an additional transverse bandage around the region prone to delamination. Which was contained but not completely prevented? The third design overcomes the problem by ending the fibers at the end of the eye section.

[31] attempted to design and evaluate the performance of double bolted end joint for thermoplastic composite leaf springs. Injection molded $20 \%$ glass fiber reinforced polypropylene leaf springs were considered for the joint strength evaluation. Universal servo hydraulic facility (Insrton 8801) was used for testing joint strength under static and dynamic conditions. Double bolted joint with steel plate. Load-deflection hysteresis plot of the investigated joint under fatigue 
loading was used as the bearing damage index. It was found to be significantly higher than that of the leaf spring design load. Bearing surface of the joint under static as well as fatigue loading condition exhibits matrix fibrillation and severe matrix deformation due to the existence of bi - axial stress condition.

[13] investigated experimentally and numerically about the influence of ellipticity ratio on performance of woven roving wrapped composite elliptical springs. A series of experiments was conducted for composite elliptical springs with ellipticity ratios $(\mathrm{a} / \mathrm{b})$ ranging from one to two. The simulation was performed using a commercial available finite element package (LUSAS). Two quadrilateral shell element types were included in the LUSAS library for thin - shell applications. Key design parameters, such as spring rate and failure load were measured as a faction of ellipticity ratio. The spring failure modes of all springs were also reported. In general, this study demonstrated that composite elliptical spring can be used for light and heavy trucks and meet the requirements, together with substantial weight saving. The results showed that the ellipticity ratio significantly influenced the spring rate and failure loads. Composite elliptic spring with ellipticity ratios of $\mathrm{a} / \mathrm{b} 2.0$ displayed the highest spring rate.

[32] conducted and experiments using UTM and on glass fiber reinforced plastic (GFRP) with the polyester resin (NETPOL 1011) composite leaf spring. A spring with constant width and thickness was fabricated by hand lay - up technique. Numerical analysis via (FEA) using ANSYS software. Stress and deflection results were verified for analytical and experiment results. Result shows that, the composite spring has stresses much lower than steel leaf spring and weight of composite spring was nearly reduced up to $85 \%$.

[47] investigated the effect of whole notch size and the specimen width of the notched strength of woven carbon fiber reinforced plastic (CFRP) composites. It was found that a notch sensitivity coefficient can be modeled as a function of specimen geometry and the mechanical property. They also investigated the effect of the specimen geometries on the strength of composites and obtained failure strengths of prepared specimens by static fracture test.

[21] examined, the effects of resin content and the wear of woven rolling glass fiber epoxy resin and glass fiber polyester resin composite materials. Furthermore, composite material was experimentally investigated under different loads and speeds by using block on shaft wear tester. The glass fiber epoxy resin and glass fiber polyester resin composite materials specimens have been tested under different experiment conditions. The amount of wear was measured before the experiment and after the experiment with the apparatus of balance scales with the accuracy of $10^{-3}$ g. Glass fiber epoxy resin composites generally showed higher strength and minimum wear when compared with glass fiber polyester resin composites materials.

[11] examined the effects of various loading conditions on the stress of a pin-loaded woven-glass fiber reinforced epoxy laminate conveying chain component. The stress analysis around the pin hole of conveying chain component has been examined numerically and experimentally. An apparatus was developed to simulate chain components in real motion. Two different working conditions of the chain component were investigated. The first condition represents the movement of the chain components without loading. In the second condition, the chain component touches and moves the load. At the all loads $(250,500,750,1000,1250 \mathrm{~N})$ and at the all working conditions, the maximum compression stress occurs on the load acting point and inner face of pin hole. At the first working condition of the study the maximum stress compression was lower than the second working condition where the components begin to touch the load and drift it.

[3] presented a theoretical and experimental study dealing with the mechanical behavior of variable thickness composite structures.This study evaluated longitudinal and interlaminar normal and shear strains in order to find out what happens inside the laminate when a transverse load was applied to a variable thickness laminated composite beam. A finite element model was used for calculating the strain components. Failure prediction was carried out by means of a quadratic failure criterion. The accuracy of the theoretical model as well as study of different failure mechanisms that appear in a variable thickness composite beam when subjected to a transverse load. AS4/3501-6 Graphite/Epoxy was used for this work. Longitudinal and interlaminar strains were measured using strain gauges. An excellent agreement was found between the data and the prediction. For high values of the angle of variation of thickness, the strength was low because of the variable thickness effect. The numerical results from theory and testing were very close in both fields: deflections, and longitudinal and interlaminar strains. Theoretical and experimental distributions of throughthickness strains are also very close.

[22] found that Leaf area index (LAI) is an important variable needed by various land surface process models. It has been produced operationally from the Moderate Resolution Imaging Spectroradiometer (MODIS) data using a look-up table (LUT) method, but the inversion accuracy still needs significant improvements. Thus proposed an alternative method in this study that integrates both the radiative transfer (RT) simulation and nonparametric regression methods. This algorithm was tested in two sites, one at Maryland, USA, a middle latitude temperate agricultural area, and the other at Canada, a boreal forest site, and LAI was accurately estimated. The derived LAI maps were also compared with those from MODIS science team and ETM+ data. In this study, an automatic soil line identification method was developed based on the pixels' red-NIR reflectance shape. However, automatic soil line identification was complicated and needs more refinements in degraded red-NIR spaces due to low spatial resolution and pixel mixing.

[48] investigated that friction and wear properties between unidirectionally oriented fibrereinforced plastics and carbon steel. A wide variety of fiber-reinforced plastics were prepared for experiments; the fiber reinforcements used were high-tensile-strength carbon fiber, high modulus carbon fibre, E-glass fibre, stainless steel fibre and aramid fibre (Kevlar-49), while epoxy resin, polyester resin and PTFE were employed as matrix material. From investigations on the 
unlubricated friction and wear between unidirectionally oriented FRP and carbon steel, the following results were obtained. The law of mixtures in the calculation of the friction coefficient of FRP was deduced, and the validity of this law was confirmed by the experimental results. CFRP gave a small specific wear rate and a low friction coefficient in contrast; GFRP and SFRP provided large specific wear rates and high friction coefficients. The lowest friction coefficient of 0.1 was obtained with CFRP.

[30] investigated that the optimum bolted joints for hybrid composite materials composed of glass-epoxy and carbonepoxy under tensile loading. The design parameters considered for the bolted joints were ply angle, stacking sequence, the ratio of glass-epoxy to carbon-epoxy, the outer diameters of washers and the clamping pressure. As bearing failure was desirable for bolted joints, the geometry of the bolted joint specimen was designed to undergo bearing failure only. The hybrid composite materials were investigated using ANSYS, commercial finite-element software, and compared with the experimental results. They concluded that a peak load occurred before the maximum failure load, which was due to delamination of the laminate under the washer. At the maximum failure load, delamination on the loaded side of the hole and the extensive buckling of plies at the washer outside edge were found.

[44] arrived that a layer-wise strength analysis of laminates leads to realistic results not only with quasistatic but also with cyclic loading. The used fatigue strength has to be determined by experiment. Manufacturing the test plates by compression-moulding different force/time pressing-cycles were performed in order to adjust different fiber volume fractions. This leads to a premature failure of the laminate much earlier as it was predicted by failure criteria. Performing 3-point-bending tests the notch effect was measured to obtain a more exact service life prediction. Adequate crack arresting layers are tested which will reduce the negative notch effect. This positive influence also exists if there are neighbouring transverse plies which early suffer IFF-cracks impacting the highly stressed glass fibers. By inserting crack arresting layers from PET or PAN in between the fatigue strength may be increased significantly even if the mechanisms are still not clarified. They showed a markedly strong adhesion and delaminations only appear in areas where the $0^{\circ}$ ply is damaged very extensively.

[14] carried out failure analysis of a leaf spring which failed prematurely during service, using optical and scanning electron microscopy, hardness and tensile testing, and residual stress evaluation by X-ray diffraction. Quench cracks, which were aligned normal to the length of the leaf, have been identified in shot peened and polished surfaces. These cracks have been attributed to an improper quenching process. It was established by theoretical analysis that the leaf thickness was smaller than the critical plate thickness required for this composition of steel, and that leads to an increase in quench severity. It appears that some of these quench cracks have propagated by a fatigue mode which is confirmed by the presence of beach marks on the fracture surface. The present failure was due to an improper quenching process which has led to the generation of quench cracks. These quench cracks have grown further by a fatigue mechanism during service. The growth rate of the cracks has been further influenced by grain boundary embrittlement due to the presence of sulphide inclusions.

[10] taken four different types of helical composite springs were made of structures including unidirectional laminates (AU), rubber core unidirectional laminates (UR), unidirectional laminates with a braided outer layer (BU), and rubber core unidirectional laminates with a braided outer layer (BUR), respectively. They investigated the effects of rubber core and braided outer layer on the mechanical properties of the aforementioned four helical springs. According to the experimental results, the helical composite spring with a rubber core can increase its failure load in compression by about $12 \%$, while the spring with a braided outer layer can not only increase its failure load in compression by about $18 \%$, but also improve the spring constant by approximately $16 \%$. The helical spring with a BUR structure has the highest mechanical properties among those considered herein, its failure load in compression approximately equals $336.2 \mathrm{kgf}$ and the spring constant is almost $16.27 \mathrm{kgf} / \mathrm{mm}$.

[45] studied the behavior of leaf springs; particular emphasis was given to unidirectional laminates which are used in this kind of structures. The investigation was carried out with the aid of numerical methods and the results have been used in the Azzi - Tsai failure criterion to predict laminate strength. It must be noted that with this laminates total failure occurs after extended damage starting at very much lower loads. In this work, only first failure was considered. Finally the behavior of multi-bolted joints was examined and differences from single bolted joints were pointed out.

[50] investigated the fundamental properties of the dimensioning of the double tapered FRP leaf springs. The optimal taper ratio was proved to be 0.5 . Prototype longitudinal type double tapered leaf springs to replace four leaf steel springs were made from glass fiber and epoxy. Prototype GRP leaf springs showed a superior endurance and fail-safe characteristics and the device for vehicle attachment was proved to have sufficient strength.

[27] used Multi-leaf springs as suspension components in some Venezuelan uses were found to fail after a short service time. The origin of premature failure in the springs was investigated. To this end, common failure diagnosis methods involving examination of manufacturing and failure histories, macroscopic inspection, chemical analysis, met allographic analysis, hardness measurements, static loading tests and fatigue tests, were employed. The studied leaf spring model was installed in 50-seat buses and subject to fluctuating loads and environmental conditions typical of an urban bus. The studied spring was subject to visual and macroscopic inspection with a magnifier. Specimens of service leaves were analysed for chemical composition of the surface and core, using a spectrolab M5 optical emission spectrometer. Specimens for met allographic analysis were prepared according to ASTM E3 standard. Specimens were subjected to Brinell hardness (HB) measurements in accordance with ASTM 110 and rock well C hardness (HRC) measurements following ASTM E18. Static loading tests were performed with a universal dynamometer. Fatigue tests 
were performed with a universal dynamometer. Fatigue tests were performed in accordance with SAE J1528 and the Venezuelan standard COVENIN 96678. It was concluded that fracture occurred by a mechanism of mechanical fatigue, initiated at the region of the central hole, which suffered the highest tensile stress levels. Several factors (poor design, low quality material and defected fabrication) have combined to facilitate failure. Preventive measures to lengthen the service life of leaf springs were also suggested.

[4] investigated the impact response of woven carbon/epoxy and E-Glass/epoxy composite systems on vehicle body structures, by considering energy profile diagrams and force displacement curves. The energy absorbed by the composite specimen through the impact event were important parameters to assess impact response of the composite structures. It was established that by increasing the impact energy elastic deformation of woven e-glass/epoxy composite systems by 1.5 times higher, than that of carbon epoxy composites systems that defines the formation of smaller areas of damage.

[33] calculated the fatigue strength of shot peened leaf springs .The axial fatigue strength of EN45A spring steel specimen was evaluated experimently as a function of shot peening in the conditions used for full scale leaf springs testing in industries. Fatigue life estimation of full scale testing of leaf springs of EN45A spring steel has been studied from its specimen from the viewpoints of stress approach. The full scale correlation factor (FSCF) decreases with decreasing stress level fatigue life estimation was good at various stress level. Wide differences in fatigue life between specimen and the full scale leaf spring testing are mainly due to fretting fatigue between mating leaves.

\section{Evaluation of leaf spring}

[18] states that the hybrid comprised of one steel primary leaf and one tapered composite epoxy-glass support leaf combines a transverse steel-composite leaf design into a multi-leaf system. The primary leaf has modeled using the surface-to-surface contact algorithm of ABAQUS. The results demonstrated the important differences between idealized non-contact models relative to a complete contact model.

[5] presented leaf spring failure during accident sequence in sports vehicle, in terms of fracture surface analysis and residual - strength was estimated by the presence of sulfur segregation weakened the spring. Fracture and cracking at the mid plane of the leaf spring was root cause for segregation and weakness in the spring.

\section{Optimization of composite leaf spring}

[42] investigated that machining process were generally used to cut,drill, or contour composite laminates for building products. Machining of fiber reinforced plastic (FRP) components was often needed process for fiber reinforced materials. The experimental results indicated that the specimen thickness, feed rate and cutting speed were reckoned to be the most significant factors contributing to the deflamation. A signal-to-noise ratio was employed to analyze the influence of various parameters on peel up and push down delamination factor in drilling of glass fibre reinforced plastic (GFRP) composite laminates. They determined factor and combination of factors that influences the delamination and the using Taguchi and response surface methodology they also achieved the optimization machining conditions that would result in minimum delamination. Confirmation experiments were conducted to verify the predicted optimal parameters with the experimental results good agreement between the predicted and experimental results obtained to be of the order of $99 \%$.

[46] presented a generic method/model for multi-objective design optimization of laminated composite components, based on Vector Evaluated Artificial Bee Colony (VEABC) algorithm. VEABC was a parallel vector evaluated type, swarm intelligence multi-objective variant of the Artificial Bee Colony algorithm (ABC). In this work a modified version of VEABC algorithm for discrete variables has been developed and implemented successfully for the multiobjective design optimization of composites. The problem was formulated with multiple objectives of minimizing weight and the total cost of the composite component to achieve specified strength. The optimization method was validated for a number of different loading configurations-uniaxial, biaxial and bending loads. The design optimization has been carried for both variable stacking sequences, as well fixed standard stacking schemes and a comparative study of the different design configurations evolved has been presented. Finally the performance was evaluated in comparison with other nature inspired techniques which includes Particle Swarm Optimization (PSO), Artificial Immune System (AIS) and Genetic Algorithm (GA).

[29] presented a methodology for the multiobjective optimization of laminated composite materials that is based on the integer coded genetic algorithm. The fiber orientations and fiber volume fractions of the lamina were chosen as the primary optimization variables. Simplified micromechanics equations were used to estimate the stiffness and strength of each lamina using the fiber volume fraction and material properties of the matrix and fibers. The lamina stresses of thin composite coupons subjected to force and/or moment were determined using the classical lamination theory and the first ply failure strength was computed using the Tsai-Wu failure criterion. The result demonstrates the effectiveness of the proposed methodology to the multi objective optimization of composite materials. 


\section{Conclusion}

The leaf springs are designed by considering as it is behave like a cantilever beam. This paper has provided a brief summary research on composite leaf spring. For the past three decades, this paper elaborately provides the research work carried out by various researchers on material selection, manufacturing, experimental investigation, modeling and analysis and optimization of composite leaf spring. All the above parameters on composite leaf spring were discussed with comparing conventional leaf spring. The intension of the authors was simply to provide ground work to readers those who are interested looking back on the evolution of composite leaf spring. In almost all the paper it was concluded that by using composite material heavy reduction in the weight was obtained with many other advantages such as reduction in wear and noise, increasing in comfort ride, increasing fatigue life, increasing strength, etc.

\section{References}

[1] A. Gonzalez et al (2011)" Design of an adjustable- stiffness spring: Mathematical modeling and simulation, fabrication and experimental validation", International journal of Mechanism and Machine Theory.

[2] Abdul Rahim et al (2009)" Developing a composite based elliptic spring for automotive applications", International journal of Materials and Design,pp475-484.

[3] Antionio Miravete (1990)" Strain and stress analysis in tapered laminated composite structures", International journal of composite structures.pp 65-84.

[4] Arturas Kersys et al (2010) "Experimental Research of the Impact Response of E-Glass /Epoxy and carbon /Epoxy composite systems “ Materials Science Vol 16.

[5] C.k Clarke et al (2005) "Evaluation of a leaf spring failure", Journal of Failure Analysis and Prevension.

[6] C.K.H Dharan et al (2007)" Composite disc springs," International journal of applied science and Manufacturing, pp 2511-2516.

[7] C.Subramanian et al (2010) "Effect of reinforced fiber length on the joint performance of thermoplastic leaf spring", International journal of Materials and Design.3733-3741.

[8] C.Subramanian et al (2010) "Short term flexural creep behavior and model analysis of a Glass -Fiber - Reinforced Thermoplastic Composite Leaf spring", Journal of Applied Polymer Science, Vol.120, pp 3679-3686.

[9] Subramanian et al (2011) “Joint performance of the glass fiber reinforced polypropylene leaf spring”, International journal of Composite Structures,pp.759-766.

[10] Chang - Hsuan Chiu et al (2007)" An experimental investigation into the mechanical behaviors of helical composite springs", International journal of compositestructures.pp 331-340.

[11] Cicek Ozes et al (2004) "Stress analysis of pin- loaded woven - glass fiber reinforced epoxy laminate conveying chain components",International journal of composite structures.pp 470-481.

[12] Crivelli Visconti et al (1990) "Forecast on structural behavior for a composite city bus in GRFP", Journal of composites manufacturing.

[13] E.Mahdi et al (2006) "Light composite elliptic springs for vehicle suspension", International journal of Composite Structures,pp.24-28.

[14] Erol Sancaktar et al (1999) "Design,analysis and optimization of composite leaf springs for light vehicle applications", International journal of Composite Structures,pp.195-204.

[15] F. Guttman et al (1994) " On the numerical analysis of local effects in composite structures " Composite Structures, pp 1-12.

[16] F.N. Ahmad Refngah et al (2009) "Life Assessment of a Parabolic Spring Under Cyclic Strain Loading “ European Journal of Science Research. Vol 28, pp 351-353.

[17] G.Goudah, et al (2006) “Automobile compression composite elliptic spring “, International journal of Engineering and Technology, Vol3,pp 139-147.

[18] Gary Leavy (2004)" Evaluation of a Multi- Leaf Hybrid Springs for Automotive suspensions" SAE International.

[19] Gulur siddaramanna shiva Shankar et al (April 2006) “Mono Composite leaf spring for light vehicle - Design, End joint Analysis and Testing", International journal of Materials science, Vol.12

[20] H.A. Al- Qureshi et al (2001)" Automobile leaf spring from composite materials ", International journal ofMaterials Processing Technology,pp. 58-61.

[21] Hasim Pihtili (2008)" An experimental investigation of wear of glass fibre-epoxy resin and glass fibre - polyester resin composite materials"”, European polymer journal, pp 149-154.

[22] Hongliang Fang et al (2004) "A hybrid inversion method for mapping leaf area index from MODIS data: experiments and application to broadleaf and needle leaf canopies",Journal of Remote sensing of environment ,pp 405-424.

[23] Horiyuki Sugiyama et al (2005)" Development of nonlinear elastic leaf spring model for multibody vehicle systems",International journal of computer methods inapplied mechanics and engineering,pp6925-694.

[24] Hossein Ghiasi et al ( 2009) "Optimum Stacking sequence design of composite materials part1: Constant stiffness design “, International journal of Composite Structures,pp.1-11.

[25] I.Rajendran et al (2001) “ Optimal design of a composite leaf spring using genetic algorithms", International journal of computers and structures,pp1121-1129.

[26] J. Anders Holmberg (1995) "Application of weibull theory to random-Fibre composites ", International journal of composites science and technology, pp 75-85.

[27] J.J.Fuentes et al (2008) “Premature fracture in automobile leaf springs”, International journal of Engineering Failure Analysis ,pp 648-655.

[28] J.P.Hou et al (2007) "Evolution of the eye-end design of a composite leaf spring for heavy axle loads", International journal of Composite structures, pp.351-358.

[29] Jacob L. Pelletier et al (2006) "Multi-objective optimization of fiber reinforced composite laminates for strength, stiffness and minimal mass “ Computer and Structures, pp 2065-2080.

[30] Je Hoon Oh et al (1997)" Optimum bolted joints for hybrid composite materials “, International journal of composite structures.

[31] Joo-teck Jeffrey kueh et al ( 2012) "Finite element analysis on the static and fatigue characteristics of composite multi- leaf spring " Journal of Zhejiang University - science A ( Applied Physics \& Engineering).pp 159-164.

[32] K.K. Jadhao et al (2011) "Experimental Investigation \& Numerical Analysis of Composite Leaf Spring”, International journal of engineering science and technology vol 3.

[33] K.K.Jadhao et al (2010)" Experimental analysis of composite leaf spring", International journal of Engineering and Technology.

[34] Krishnan Kumar et al (2013) "Computer aided FEA simulation of EN45A parabolic leaf spring" International journal of industrial Engineering and Computations, pp 297-304.

[35] M.F.Ashby et al (2003)” Designing hybrid materials”, International journal of acta materials, pp5801-5821. 
[36] M.M.Patunkar et al (2011) "Modelling and Analysis of Composite leaf spring under the static load condition by using FEA", International journal of Mechanical and Industrial Engineering, Vol 1, pp.1-4.

[37] M.Senthil Kumar et al (2006) "Static analysis and fatique life prediction of steel and composite leaf spring for light passenger vehicles", Journal of scientific \& Industrial Research, pp128-134.

[38] Mahmood M. Shokreih et al (2003) "Analysis and optimization of a composite leaf spring", International journal of Composite Structures,pp.317-325.

[39] Mouleeswaran senthil kumar et al (May 2007) “ Analytical and Experimental studies on Fatigue life prediction of Steel and composite Multileaf Spring for Light Passenger Vehicles Using Life data Analysis”, International journal of Materials science, Vol.13

[40] N. Sato et al (1997) "Interpretation of Acoustic Emission Signal from Composite Materials and its Application to Design of Automotive Composite Components" Springer pp 119-136.

[41] N.K Mukhopadhyay et al (1997)" Premature Failure of a leaf spring due to improper materials processing”, Journal of Engineering Failure Analysis.

[42] N.S. Mohan et al (2006)" Delamination analysis in drilling process of glass fiber reinforced plastic (GFRP) composite materials ",Journal of materials processing Technology,pp265-271.

[43] Niklas Philipson (2006)" Leaf spring modeling”, The Modelica Association.

[44] Oliver Franke et al (2010) "Analysis of the interaction of adjacent layers of a GFRP- laminate under fatigue loading”, International journal of fatigue,pp 54-59.

[45] Paolo Conti (1986) "Influence of Geometric Parameters on the stress Distribution Around a pin-loaded hole in a Composite laminate" Composite Material Technology, pp 83-101

[46] S.N. Omkar et al (2009) "Artificial Bee Colony (ABC) for multi- objective design optimization of composite Structures", Journal of applied soft computing,pp 489-499.

[47] Sang- young Kim et al (2011)" Prediction of the static fracture strength of hole notched plain weave CFRP Composite,pp 1-21.

[48] T.Tsukizoe et al (1983)" Friction and Wear of Advanced Composite Materials “, Journal of fibre science and Technology, pp265-286.

[49] V Ravikumar et al (2013) “ Analysis of Natural Fiber Composite Leaf spring” International Journal of Latest trends in Engineering and Technology, pp182-191

[50] W.J.Yu et al (1988)" Double Tapered FRP Beam for Automotive Suspension Leaf Spring” Computer and Structures, pp 279-300. 